\title{
Vocal cordopathy consequent to bronchial asthma inhalation therapy
}

\author{
Ahmed Mohammed Abumossalam ${ }^{1,2^{*}}$ (D), Hanan Abdelsattar Ahmed ${ }^{3,4}$, Omar Mohamed Ibrahim ${ }^{5,6}$, \\ Talal Mohamad Saad Algreisy ${ }^{7}$ and Abdullah Mohmad Al-Shenqiti ${ }^{8}$
}

\begin{abstract}
Background: Vocal cords signify an imperative lane for air flow in and out of the respiratory tract along with a phonetic role. So, the aim of this work is to assess the impact of habitual versus occasional utilization of inhalation therapy of patients with bronchial asthma on their vocal cords regarding visual endoscopic pathological changes in addition to phonetic dysfunction. This study was conducted on 112 diagnosed bronchial asthma patients (66 male and 46 females). They were classified into the following: group A (habitual user), 65 patients with severe persistent asthma with regular frequent intake of inhalation therapy, and group B (occasional user), 47 patients with intermittent asthma with alternating intake of inhalation therapy. They were submitted to clinical, vocal assessment plus laryngoscopic examination.

Results: The habitual users group demonstrated that laryngeal edema and hyperemia attained the higher percentage in the adult than children age group (60\%,40-67.3\%, 50\%) respectively together after 6 and 9 months of study followed by laryngeal nodules $(5.4 \%, 0-9 \%, 10 \%)$. Occasional users presented the same findings comparable to the habitual group $(27 \%, 10-32.4 \%, 20 \%)$. Cord paresis, cord dysfunction, and fungal plaques were in the second frequencies in both age groups with the same percentage (3.6\%) at the end of the study; however, in occasional users, fungal plaques illustrated low percentage $(2.7 \%, 5.4-0,10 \%$, respectively).

Conclusion: Inhalation therapy as a form of asthma medication correlated with major counter effects on vocal cords with well-recorded laryngeal hyperemia, edema, and vocal nodules in addition to fungal plaques moreover phonetic dysfunction.
\end{abstract}

Keywords: Vocal cords, Nodules, Inhalation therapy, Hyperemia, Dysphonia

\section{Background}

Bronchial asthma had long been considered the major airway disease associated with reversible airflow obstruction, airway hyperresponsiveness, and small and large airway inflammation. Inhalation therapy with bronchodilator in the form of long-acting $\beta 2$ adrenergic agonists (LABAs) as reliever medications and anti-inflammatory drugs likecorticosteroids as controller ones basically

\footnotetext{
* Correspondence: abumossalam79@yahoo.com

${ }^{1}$ Thoracic Medicine Department, Faculty of Medicine, Mansoura University, Mansoura, Egypt

${ }^{2}$ Respiratory Therapy Department, Faculty of Medical Rehabilitation Sciences, Taibah University, Al-Medinah Al-Munwarah, Kingdom of Saudi Arabia

Full list of author information is available at the end of the article
}

established the cornerstone treatment for most patients with different disease severities. Predictably, therapeutic efficacy was assessed on the basis of manner of drug delivery as well as improvement in symptoms and lung functions [1]. Patients managed with steroids were found to develop inhaler laryngitis ranging from mucosal erythema, edema, and thickening to granulation, leukoplakia, and candidiasis. More severe mucosal findings in those cases manifested as laryngopharyngeal reflux. Recovery from of dysphonia occurred only after withdrawal of the inhaled steroid therapy [2]. The phonatory side effects of different compositions of both were widely documented. However, there was limited or incomplete understanding of the physiological alterations prompted

\section{Springer Open}

(c) The Author(s). 2020 Open Access This article is licensed under a Creative Commons Attribution 4.0 International License, which permits use, sharing, adaptation, distribution and reproduction in any medium or format, as long as you give appropriate credit to the original author(s) and the source, provide a link to the Creative Commons licence, and indicate if changes were made. The images or other third party material in this article are included in the article's Creative Commons licence, unless indicated otherwise in a credit line to the material. If material is not included in the article's Creative Commons licence and your intended use is not permitted by statutory regulation or exceeds the permitted use, you will need to obtain permission directly from the copyright holder. To view a copy of this licence, visit http://creativecommons.org/licenses/by/4.0/. 
by these medications that lay beneath the phonatory side effects [3]. Among the most common local adverse effect of inhaled corticosteroids (ICS) therapy was dysphonia that had been reported in 5 to $58 \%$ of patients. Although causes of dysphonia associated with ICS therapy had not been scoped out, it might result from deposition of an active molecule in the oropharynx during supplementation, which then led to myopathy or a mucosal effect in the laryngopharynx [4]. Awareness of the physiological changes to the vocal folds after corticosteroid and LABA treatments was a mandate to limit the prevalent vocal functional decrement linked to these medications. It was suggested that one implied physiological mechanism for phonatory changes associated with inhaled long-acting $\beta 2$ agonist inhaled treatments might be related to acute alterations in vocal fold ion transport and mucosal surface hydration [5]. Overall inhaled therapy for bronchial asthma patients showed direct hazards depending on the type and frequency of supplementation. So, the aim of this cross-sectional study was to assess the impact of habitual versus occasional utilization of inhalation therapy of patients with bronchial asthma on their vocal cords regarding visual endoscopic pathological changes in addition to phonetic dysfunction.

\section{Methods}

\section{Study type}

This is a prospective observational longitudinal study (depending that patients continued on their current medication, no intervention, with repeated observation) which was carried out on 135 well-proven and recently diagnosed bronchial asthma (within 3 months prior study) patients from age 10 to 50 years. They were recruited from the outpatient pulmonology clinics from Taibah medical services center, Al-Medina AlMunwarah, Kingdom of Saudi Arabia. Only 112 patients completed the study (66 male and 46 females; 92 adults aged 25-50 years and 20 children in the age group 1018 years) who were adherent to inhaler therapy for 9 months from February 2019 to December 2019. They were classified into two groups taking GINA 2002 into consideration according to the medical recording system of cases in Taibah Medical center outpatient clinics:

Group A (habitual user): involved 65 patients with severe persistent asthma (step 4) with regular frequent intake of inhalation therapy; daily utilization of their inhaler devices.

Group B (occasional user): 47 patients with intermittent asthma (step 1) with alternating intake of inhalation therapy; utilization of their inhaler devices $\leq$ once per week.

Preliminary written consent was taken from patients or children's relatives. Departmental institutional review board agreement and ethical approval were taken. No spacer was used in the children age group.

\section{Diagnostic procedures}

The study was accomplished at three visits: visit 1 , beginning of study; visit 2, after 6 months; and visit 3, at the end of study ( 9 months). Patients continued on their current medication (inhaled steroid and LABA in the form of fluticasone propionate plus salmeterol xinafoate (accuhaler) plus salbutamol as a reliever medication) with both forms metered dose inhaler (MDI) \pm drypowder inhaler (DPI) accuhaler.

Patients were subjected to the following:

1. Patient's assessment: included study of the patient's complaint (harsh cough, dysphonia, phonasthenic symptoms, and laryngeal soreness) and type and grade of asthma severity according to GINA 2002.

2. Vocal assessment: listening to the patient's voice, auditory perceptual assessment was performed using the modified GRBAS scale [6], and voice was assessed commenting on the following parameters: (a) dysphonia; (b) character (quality) of voice: strained (S), leaky (L), breathy (B), and irregular "rough"; (c) pitch: normal or decreased; and (d) loudness: normal or decreased.

3. Laryngeal assessment: asthmatic patients included in our study were referred to ENT (ear, nose, and throat) department where laryngeal examination by ENT consultant was conducted for those patients in the intervention endoscopy room (Fig. 2) with the help of laryngovideostroboscopy that was performed using a digital stroboscopy unit (Model 9100 B; Kay Elemetrics Corp., Lincoln Park, NJ, USA) and connected to a CCD camera (Model 9111; Panasonic, Yokohama, Japan) under local spray and nebulized anesthesia with lidocaine $2 \%$.

Patients with pathological lesions (nodules, polyps, and plaques) were sent to the ENT department in the International Medina Hospital, were subjected to tracheal swap and biopsy maneuver with Chevalier-Jackson Cup Shaped Biopsy Forceps Straight $35 \mathrm{~cm}$, and were sent for histopathology.

Classification of cases into occasional user and habitual user was based on necessity to use both medication in different forms such as reliever medication and controller medication, so studying the hazards of $\beta 2$ agonist alone and steroid alone was not applicable in this health institute because of the difficulty in isolation of medications and restriction of device supplementation as well as the deprivation of these cases from lifesaving medication for both bronchodilator or anti-inflammatory benefits. 


\section{Exclusion criteria}

1. Age above 50 or below 10 years

2. Cases who showed any laryngeal complaints or endoscopic findings at visit 1 were excluded from the study

3. Status asthmaticus/COPD

4. Non-adherent patients on inhaler therapy in the past 9 months

5. ABPA

6. Connective tissue disease

7. Occupational asthma or history of inhalation injury

8. Smokers

9. Comorbidities such as congestive heart failure, renal failure, and liver cell failure

\section{Clinical diagnostic aids}

Recording and examination of the following was done (primary laryngeal endoscopic findings were recorded (Figs. 1)):

1. Laryngeal edema and hyperemia

2. Laryngeal nodule and polyp/s

3. Vocal cord mobility, paresis

4. Vocal cord atrophy, bowing

5. Cord dysfunction

6. Plaques

7. Glottis gap

\section{Statistical analysis}

Data were analyzed using SPSS (Statistical Package for Social Sciences) version 21. Qualitative data were presented as number and percentage. Quantitative data were presented for normality by Kolmogorov-Smirnov test. Normally distributed data were presented as mean and standard deviation. Comparison between groups was done using chi-square test. Student's $t$ test was used to compare between the two groups. $P$ value $<0.05$ was considered significant. (Figs. 1 and 2).

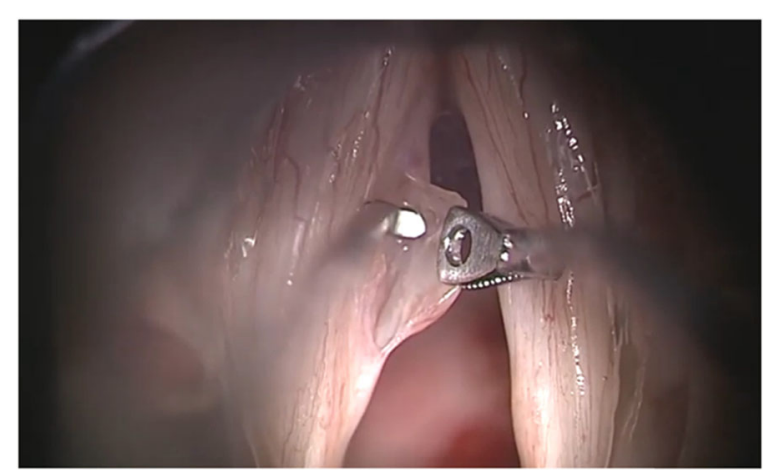

Fig. 1 Endoscopic view of laryngeal left vocal cord nodule during forceps excision

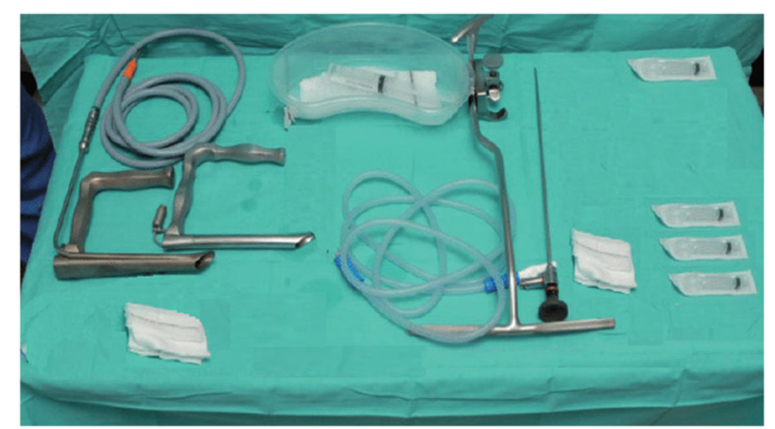

Fig. 2 Laryngoscope and rigid type with instruments used in the theater

\section{Results}

Table 1 demonstrates that the mean age for adult habitual user ( 42 years) was higher than adult occasional user (33 years) with statistically significant differences. The children group demonstrates also higher age in habitual than occasional user (13-10 years). Male predominance was common in both habitual and occasional user jointly in age groups but without statistical significant differences.

Table 2 showed that as regards clinical and vocal findings, habitual users showed that harsh cough and laryngeal soreness attained higher percentage in studies cases $(63.6 \%, 60-80 \%, 70 \%)$ in adult and children respectively followed by strained voice and dysphonia in adult. Phonasthenia was found to be higher in children than adults $(40 \%, 10 \%)$. Occasional users showed predominance of harsh cough and soreness in children than adult group dysphonia and phonasthenia, and strained character prevailed in the adult group but was absent in children one $(16.2 \%, 24.3 \%$, and $13.5 \%$, respectively). Statistical significant differences were detected between the 4 groups regarding harsh cough and soreness (0.045 and 0.027) respectively.

In Table 3, regarding visual endoscopic findings, the habitual users group demonstrated that laryngeal edema and hyperemia attained the higher percentage in adult than children age group $(60 \%, 40-67.3 \%, 50 \%)$ respectively together after 6 and 9 months of study followed by laryngeal nodules $(5.4 \%, 0-9 \%, 10 \%)$. Occasional users presented the same findings comparable to the habitual group (27\%, 10-32.4\%, 20\%). Cord paresis, cord dysfunction, and plaques were the second percentages in both age groups with the same percentage $(3.6 \%)$ at the end of the study; however, in occasional users, plaques illustrated low percentage $(2.7 \%, 5.4-0 \%, 10 \%)$ respectively with the absence of other endoscopic findings except cord dysfunction (2.7\% in adult group). Statistical significant differences were detected between the 4 groups regarding laryngeal edema hyperemia and laryngeal nodules $(0.0032,0.0021)$ respectively. 
Table 1 Demographic data in studied population

\begin{tabular}{llll}
\hline & Group A (habitual user), no $=65$ & Group B (occasional user), no $=47$ & $\boldsymbol{P}$ value \\
\hline Age & & \\
Adult age (mean \pm SD) (years) & $42 \pm 11.23$ & $33 \pm 9.05$ & $10 \pm 2.3$ \\
$\quad$ Children age (mean \pm SD) (years) & $13 \pm 5.2$ & \\
Sex & & $18(19.5 \%)$ \\
Adult group $(\boldsymbol{N}=\mathbf{9 2 )}$ & $35(38 \%)$ & $19(20.6 \%)$ \\
$\quad$ Male $(N=53)$ & $20(21.7 \%)$ & \\
$\quad$ Female $(N=39)$ & & $7(35 \%)$ \\
Children group $(\boldsymbol{N}=\mathbf{2 0})$ & $6(30 \%)$ & $3(15 \%)$ \\
$\quad$ Male $(N=13)$ & $4(20 \%)$ & 0.0285 \\
Female $(N=7)$ &
\end{tabular}

Biopsy was carried out in accessible visible endoscopic lesions (polyps and nodules and plaques) that were encountered in 15 cases (total cases = after 9 months) included in our study. All cases were proved to benign lesions (5 cases represented juvenile papilloma, 3 in adults and two in children, and 5 cases were fibroma, 4 in adults and 1 in children); 7 cases of plaques were proved to be caused by fungal monilial infection (4 in adults and 3 in children).

Duration of exposure might entail a significant factor regarding the increased incidence of complications of inhaled therapy between 6 and 9 months which was the end of study. Habitual user showed higher incidence by $18 \%$ in adults and $30 \%$ in children. Occasional users showed on the other hand higher incidence by 8 in adults and $20 \%$ in children. Laryngeal hyperemia followed by nodules presented higher percentage of occurrence than other findings.

\section{Discussion}

Vocal cords entail its significance owing to their location in the midway between the oral and nasal cavities in one hand and respiratory tree in the other hand; hence, any complaints involving both cavities as well as respiratory tract have their direct impact on gross and fine vocal cord actions. Bronchial asthma represents the most common and popular airway inflammatory disease that requires multiple modalities for its management; one of the most eminent lines is inhalation therapy that symbolizes reliever and rescue medications.

Asthmatic adult and child patients received inhalation therapy directly in repetitive frequency as a habitual medication either as a necessary manner or a routine manner. They also may use this therapy as a false belief that without inhaler, the patient may be at risk of a lethal attack whatever the current condition. Inhaler

Table 2 Clinical and vocal phonetic findings in studied cases

\begin{tabular}{|c|c|c|c|c|c|}
\hline \multirow[b]{2}{*}{ Clinical findings } & \multicolumn{2}{|c|}{ Group B, occasional user, no = 47} & \multicolumn{2}{|c|}{ Group A, habitual user, no = 65} & \multirow[t]{2}{*}{$\boldsymbol{P}$ value } \\
\hline & Adult age $(\boldsymbol{N}=55)$ & Children age $(\boldsymbol{N}=10)$ & Adult age $(\boldsymbol{N}=37)$ & Children age $(\boldsymbol{N}=10)$ & \\
\hline \multicolumn{6}{|l|}{ Dysphonia } \\
\hline After 6 months & $7(12.7 \%)$ & $3(30 \%)$ & $3(8.1 \%)$ & 0 & \multirow[t]{2}{*}{0.382} \\
\hline End of study & $10(18.2 \%)$ & $4(40 \%)$ & $6(16.2 \%)$ & 0 & \\
\hline \multicolumn{6}{|c|}{ Phonasthenia low-pitched sound } \\
\hline After 6 months & $3(5.4 \%)$ & $3(30 \%)$ & $6(16.2 \%)$ & 0 & \multirow[t]{2}{*}{0.655} \\
\hline End of study & $6(10.9 \%)$ & $4(40 \%)$ & $9(24.3 \%)$ & 0 & \\
\hline \multicolumn{6}{|l|}{ Strained character } \\
\hline After 6 months & $5(9 \%)$ & $2(20 \%)$ & $4(10.8 \%)$ & 0 & \multirow[t]{2}{*}{0.730} \\
\hline End of study & $12(21.8 \%)$ & $3(30 \%)$ & $5(13.5 \%)$ & 0 & \\
\hline \multicolumn{6}{|l|}{ Harsh cough } \\
\hline After 6 months & $25(45.4 \%)$ & $6(60 \%)$ & $20(54 \%)$ & $6(60 \%)$ & \multirow[t]{2}{*}{0.045} \\
\hline End of study & $35(63.6 \%)$ & $8(80 / \%)$ & $28(75.6 \%)$ & $9(90 \%)$ & \\
\hline \multicolumn{6}{|l|}{ Soreness } \\
\hline After 6 months & $30(54.5 \%)$ & $5(50 \%)$ & $20(54 \%)$ & $6(60 \%)$ & \multirow[t]{2}{*}{0.027} \\
\hline End of study & 33 (60\%) & 7 (70\%) & $26(70.3 \%)$ & 7 (70\%) & \\
\hline
\end{tabular}


Table 3 Laryngeal endoscopic characters of studied groups

\begin{tabular}{|c|c|c|c|c|c|}
\hline & \multicolumn{2}{|c|}{ Group A, habitual user, no = 65} & \multicolumn{2}{|c|}{ Group B, occasional user, no = 47} & \multirow[t]{2}{*}{$\boldsymbol{P}$ value } \\
\hline & Adult age $(\boldsymbol{N}=55)$ & Children age $(\boldsymbol{N}=10)$ & Adult age $(\boldsymbol{N}=37)$ & Children age $(\boldsymbol{N}=10)$ & \\
\hline \multicolumn{6}{|l|}{ Visual endoscopic findings } \\
\hline After 6 months & $42(76.3 \%)$ & $6(60 \%)$ & $12(32.4 \%)$ & $1(10 \%)$ & \\
\hline End of study (total No) & $52(94.5 \%)$ & $9(90 \%)$ & $15(40.5 \%)$ & $3(30 \%)$ & \\
\hline \multicolumn{6}{|c|}{ 1. Laryngeal edema and hyperemia } \\
\hline After 6 months & $33(60 \%)$ & $4(40 \%)$ & $10(27 \%)$ & $1(10 \%)$ & 0.0032 \\
\hline End of study (total No) & $37(67.3 \%)$ & $5(50 \%)$ & $12(32.4 \%)$ & $2(20 \%)$ & \\
\hline \multicolumn{6}{|l|}{ 2. Laryngeal nodule/s } \\
\hline After 6 months & $3(5.4 \%)$ & 0 & $1(2.7 \%)$ & 0 & 0.0021 \\
\hline End of study (total No) & $5(9 \%)$ & $1(10 \%)$ & $1(2.7 \%)$ & 0 & \\
\hline \multicolumn{6}{|l|}{ 3. Laryngeal polyp/s } \\
\hline After 6 months & $1(1.8 \%)$ & 0 & 0 & 0 & ----o- \\
\hline End of study (total No) & $1(1.8 \%)$ & 0 & 0 & 0 & \\
\hline \multicolumn{6}{|l|}{ 4. Cord paresis } \\
\hline After 6 months & $1(1.8 \%)$ & 0 & 0 & 0 & 0.865 \\
\hline End of study (total No) & $2(3.6 \%)$ & $1(10 \%)$ & 0 & 0 & \\
\hline \multicolumn{6}{|l|}{ 5. Vocal folds atrophy } \\
\hline After 6 months & $1(1.8 \%)$ & 0 & 0 & 0 & - \\
\hline End of study (total No) & $1(1.8 \%)$ & 0 & 0 & 0 & \\
\hline \multicolumn{6}{|l|}{ 6. Vocal folds bowing } \\
\hline After 6 months & $1(1.8 \%)$ & 0 & 0 & 0 & 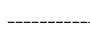 \\
\hline End of study (total No) & $1(1.8 \%)$ & 0 & 0 & 0 & \\
\hline \multicolumn{6}{|l|}{ 7. Cord dysfunction } \\
\hline After 6 months & $1(1.8 \%)$ & $1(10 \%)$ & 0 & 0 & 0.842 \\
\hline End of study (total No) & $2(3.6 \%)$ & $1(10 \%)$ & $1(2.7 \%)$ & 0 & \\
\hline \multicolumn{6}{|l|}{ 8. Plaques } \\
\hline After 6 months & $1(1.8 \%)$ & $1(10 \%)$ & $1(2.7 \%)$ & 0 & 0.754 \\
\hline End of study (total No) & $2(3.6 \%)$ & $2(20 \%)$ & $2(5.4 \%)$ & $1(10 \%)$ & \\
\hline \multicolumn{6}{|l|}{ 9. Glottis gap } \\
\hline After 6 months & 0 & 0 & 0 & 0 & ----- \\
\hline End of study (total no.) & $1(1.8 \%)$ & 0 & 0 & 0 & \\
\hline
\end{tabular}

therapy being as a local remedy signified its negative feedback from the method of delivery, nature and size of molecules, velocity of applicant devices, and duration of tissue contact till complete elimination from this site then absorption into systemic circulation. Furthermore, the patient power, compliance, and adherence of treatment imply an important factor in occurrence or absence of hazards.

Regarding visual endoscopic findings, in our work, adult habitual users were proved to have laryngeal edema and hyperemia (76.3\% after 6 months and 95\% after 9 months) while child habitual users showed $40 \%$ after 6 months and 50\% after 9 months verifying a wellestablished irritant effect with cumulative outcome after prolonged exposure. The same was found regarding nodules and fungal plaques. Adult occasional users presented lower percentage of occurrence (27\% after 6 months and 32\% after 9 months); also, child occasional users revealed lowest percentage that confirmed cause relation with cumulative results with the absence of other endoscopic findings except cord dysfunction $(2.7 \%$ in the adult group).

A study handled by John stated that the physical changes that are seen in the larynx of patients using inhaled fluticasone range from minimal to severe. Mild physical findings include edema and erythema. Moderate changes include mucosal thickening and vocal cord bowing. The most dramatic changes include leukoplakia, 
granulation, and laryngeal candidiasis. Many of these findings can also be seen with laryngopharyngeal reflux, and differentiating these 2 possible pathogenetic factors can be difficult if one is not familiar with steroid induced laryngitis [2].

The benign nature of lesions after sampling and histopathology denied hazards of malignant transformation of lesions induced mostly or associated with therapy.

The duration of exposure might entail a significant factor regarding the increased incidence of complications of inhaled therapy between 6 and 9 months which was the end of study. Habitual user showed higher incidence by $18 \%$ in adults and $30 \%$ in children. Occasional users showed on the other hand higher incidence by $8 \%$ in adults and $20 \%$ in children. Laryngeal hyperemia followed by nodules presented higher percentage of occurrence than other findings.

The study conducted by Barnes et al. stated that the frequent use of higher doses of ICS had been associated with both systemic as well as local side effects. The results of this study discovered more laryngeal irregularities in group A (patients with ICS) than in group B (patients without ICS). Group A showed the following: vocal fold congestion either localized or diffuse, hypertrophy of ventricular band, incomplete closure of glottis, and glottic gap. Moreover, a decrease in glottic wave and amplitude was identified [7].

In our words, these findings could be attributed to many factors; firstly was the adherence and accuracy of technique of inhaler handling that were efficient in adults than children in a second prolonged duration of inhaler application, as well as culture of adult which compelled them to frequently intake medications for fear of lethal attack of asthma. Secondly were the morphological and geometric considerations of difference between adult larynx and pediatric one for the drug deposition. Thirdly was the molecular features of drugs that could be identified and needed more collaboration with pharmaceutical studies.

Natasha et al. conducted a retrospective review of 10 consecutive patients, who attended at the voice center for more than 1 month of dysphonia after beginning a combination form of asthma medication as a controller and maintenance therapy. All patients in the study were nonsmokers and showed negative history of previous vocal complaints. Video-stroboscopic laryngeal examination was done for all patients. A questionnaire regarding their observed voice change and history of asthma therapy was taken. Dysphonia was detected in the patients included for greater than 4 weeks. In $8 / 9$ of patients, the vocal folds demonstrated hyperemic areas, with plaque-like features on its surface mucosa. Reduction of amplitude of vibration and a reduction in mucosal wave propagation were found on video-stroboscopy [8].
Our patients showed, in favor, that clinical and vocal findings in habitual users showed predominance of harsh cough and laryngeal soreness in studies adults and children $(63.6 \%, 60-80 \%, 70 \%)$ respectively followed by strained voice and dysphonia mainly in adults. Phonasthenia was found to be higher in children than in adults $(40 \%, 10 \%)$. Occasional users showed high proportion of harsh cough and soreness in children than in the adult group; however, dysphonia phonasthenia and strained character prevailed in the adult group; on the other hand, they were absent in children $(16.2 \%, 24.3 \%$, and $13.5 \%$, respectively).

Besides, Barnes et al. declared that acoustic analysis showed major increase in the Jitter and Shimmer percentage. Dysphonia was detected in 19 patients (76\%) of group A, six patients (24\%) with dysphonia grade 1, 10 patients $(40 \%)$ with dysphonia grade 2 , and three patients (12\%) with dysphonia grade 3 , in that their voice was perceived whichever as strained, leaky, or of rough characters [7].

Another study conducted by Lavy et al. [9] on 38 patients with bronchial asthma had the same findings. Dysphonia was found in 34 patients (89\%). They cited a variable and reversible degrees of dysphonia in their patients who did not apt well with the prolonged use of ICS and induced myopathy by them. It had been postulated that the main reason of dysphonia in some cases was steroid myopathy disturbing the muscles of vocal fold. Thus, there was bilateral adductor vocal fold deformity with vocal folds bowing on phonation [10]. This problem was, conversely, to be reversed when therapy with the inhaled steroid had stopped. The affected acoustic parameters were explained by the fact that the oscillating character of the vibratory edges and their mechanical properties in the vocal folds are sensitized by the pathological effects such as irregularities in the free edge of vocal folds or congestion. These structural changes initiated disturbing mechanical sequences, an atypical vibratory pattern, asymmetry in vibration of vocal fold, and tissue aspects with a subsequent alteration of the acoustic parameters.

In favor of voice nature, in the study by Attef et al. [11], it was mainly strained and leaky in group A patients. Grade 1 strained voice was present in $28 \%$ of cases and leaky voice of grade 1 in $28 \%$ of cases. Rough voice of grade 1 was also found in 8 patients (32\%) and grade 2 in 2 patients (8\%). The patient's effort to compensate for the small glottis gap by performing glottic and supraglottic hyperactivity elucidated the appearance of the strained cords causing a tense voice. Dogan et al. [12] detected impaired voice quality in $17.5 \%$ of patients which is lower than that in this study. In their former study, patients in group A showed diffuse congestion in $20 \%$, localized congestion in $40 \%$, ventricular folds 
hypertrophy in 56\%, vocal fold hypertrophy in $4 \%$, and glottic gap in $16 \%$. Hanania et al. [13] reported that these results could be described by the irritation of the laryngeal mucosa or by medical deposits from the inhaled steroids. As regards stroboscopic examination of group A patients, glottic wave and amplitude were diminished in both vocal folds in $32 \%$, in $8 \%$ of the right vocal fold, and in $20 \%$ of the left vocal fold and were asymmetric in phase in $56 \%$ and also were asymmetric in amplitude in $48 \%$.

It was reported by Kotby [6] that any minimal aberration of acoustic parameters may affect the pathological changes in voice. These consequences were comparable to the findings of Koike et al. [14], who revealed that voice pathology can cause augmented noise components in the voice signal such as major frequency and turbulent noise, besides voice breaks. The study by Roland et al., on the influence of ICS on voice, found high incidence of frequency and amplitude worry values (jitter and shimmer) in patients who had taken ICS with high doses and for a prolonged time [15].

Local adverse effects had been reported with all forms of inhaled corticosteroids, including beclomethasone dipropionate, triamcinolone, and budesonide acetonide. As such, approving methods to lessen inhaled steroidrelated oropharyngeal adverse effects such as rinse mouth, gargling with water after use, or the use of inhaled steroids with an upgraded safety profile considered the primary method in asthma management to decrease the impact of adverse effects [16].

Adel M. Saeed et al. declared in their study in 2018 [17] that impaired voice quality and various grades of dysphonia were detected in in $30 \%$ of the COPD group of patients by means of auditory perceptual assessment; structural changes in the vocal folds (diffuse congestion, unhealthy mucosa, and edema) were detected in $36.6 \%$. In the bronchial asthma group, impaired voice quality and various grades of dysphonia were detected in $16.7 \%$ and structural changes were detected in $20 \%$ of them, whereas acoustic analysis showed a highly significant increase in jitter and shimmer and decreased harmonic-to-noise ratio in $100 \%$ of patients of both groups. These changes were greater in metered dose inhaler users than in dry-powder inhaler users. In the bronchial asthma group, fluticasone propionate users had a significantly decreased harmonic-to-noise ratio compared with beclomethasone dipropionate and budesonide users, as well as the least pitch and highest shimmer and jitter. A significant statistical correlation was found between ipratropium inhalation usage and increased shimmer in the COPD group. There was a highly significant correlation between spirometric severity and both grade of dysphonia and character of voice in bronchial asthma patients.
Our study faced many limitations; firstly is the stratification of age groups between adults and children; secondly was the segregation between types of inhaler devices and segregation between types of medications used which was a major obstacle which needed more research about management lines to distressed cases in each group through the study; and thirdly was studying different occupational and environmental hazards and hereditary factors that have direct influences on vocal cord pathological changes.

\section{Conclusion}

Bronchial asthma inhalation therapy showed emphatic correlations to excruciating complications on vocal cords regarding both morphological and functional aspects with well-recorded visual endoscopic lesions presented in hyperemia, nodules, and fungal plaques in addition to atrophy, cord paresis, and dysfunction. Furthermore, phonetic changes were documented in the form of dysphonia and phonasthenia.

\section{Abbreviations}

B2: Beta receptor type 2; CCD: Charge-coupled device; DPI: Dry-powder inhaler; ENT : Ear, nose, and throat; GINA: Global initiative of asthma; GRABS: Grade, roughness, asthenias, breathiness, strain; ICS: Inhaled corticosteroid; LABA: Long-acting $\beta 2$ agonist; MDI: Metered dose inhaler; $N$ : Number; SD : Standard deviation; SPSS: Statistical Package for Social Science; USA: United States of America

\section{Acknowledgements}

No other than the sharing team.

\section{Authors' contributions}

Dr. A.M. A and Dr. H.AB. A: Were the owner of the idea and proposal down righting of the study. Collected the data from the outpatient clinic and evaluated the asthmatic cases. Conducted the statistical analysis and the paper manuscript writings and repeated revisions. Dr. O.I. and Dr. T.A.: Conducted the endoscopic evaluation as well as the surgical procedure of the patients' lesions and recording of the findings. They were responsible for the final results of cases with lesions as nodules and polyps in collaboration with pathology department of the International Medina Hospital. Professor A. M. A. had the responsibility for revisions and plagiarism checking and grammar checking. All authors read and approved the final manuscript

\section{Funding}

No funding was received from any institution through this work.

Availability of data and materials

All appendices and data are available for this study.

\section{Ethics approval and consent to participate}

Our study was approved by the following ethical committees

1. Taibah University, Faculty of Medical Rehabilitation Sciences, Respiratory Department

Ethical committee number 1440-5729-12 on November 2018

Institutional review board 1440-123 on December 2018

2. Taibah University, Faculty of Medicine, Pediatric Department

Ethical committee number 1440-1528-7 on December 2018

Institutional review board 1440-123 on December 2018

3. International Medina Hospital ethical committee number 1440-42 - ENT specialty January 2019 based on Ministry of Health approval of collaboration with Ministry of Higher Education 1430-11

All cases participated in our work was informed by the study and subjected to written consent according to legalization rules in invasive procedure and 
for children; consent was taken from one of the parents. This consent was approved by the institutional review board of Taibah University and International Medina Hospital.

\section{Consent for publication}

All authors approved for publishing this paper in Egyptian Journal of Bronchology with correspondence to Dr. Ahmed Abumossalam.

\section{Competing interests}

No competing interest in research work

\section{Author details}

${ }^{1}$ Thoracic Medicine Department, Faculty of Medicine, Mansoura University, Mansoura, Egypt. ${ }^{2}$ Respiratory Therapy Department, Faculty of Medical Rehabilitation Sciences, Taibah University, Al-Medinah Al-Munwarah, Kingdom of Saudi Arabia. ${ }^{3}$ Pediatric Department, Faculty of Medicine, Mansoura University, Mansoura, Egypt. ${ }^{4}$ Pediatric Department, Faculty of Medicine, Taibah University, Al-Medinah Al-Munwarah, Kingdom of Saudi Arabia. ${ }^{5}$ Ear Nose and Throat Department, Talkha Hospital, Ministry of Health, Talkha, Egypt. ${ }^{6}$ Ear Nose and Throat Department, International Medina Hospital, Al-Medinah Al-Munwarah, Kingdom of Saudi Arabia. 'Ear nose and Throat Department, Faculty of medicine, Taibah University, Al-Medinah Al-Munwarah, Kingdom of Saudi Arabia. ${ }^{8}$ Physical Therapy Department, Faculty of Medical Rehabilitation Sciences, Taibah University, Al-Medinah Al-Munawarah, Kingdom of Saudi Arabia.

Received: 13 March 2020 Accepted: 21 May 2020

Published online: 09 July 2020

\section{References}

1. Magnussen $H$ (2003) Inhalation therapy for bronchial asthma: strategies and targets. Curr Opin Pulm Med 9(Suppl 1):S3-S7

2. John M. Del Gaudio: Steroid inhaler laryngitis, dysphonia caused by inhaled fluticasone therapy. ARCH Otolaryngol Head Neck Surg J/Nol 128, 2002.

3. Sivasankar M, Blazer-Yost B (2009) Effects of long-acting beta adrenergic agonists on vocal fold ion transport. Laryngoscope 119(3):602-607

4. César A. Galván, MD and Juan Carlos Guarderas: Practical considerations for dysphonia caused by inhaled corticosteroids. Mayo Clin Proc. September 2012;87(9):901-904

5. Mark A. Giembycz, Manminder Kaur, R. Leigh, Robert Newton, A Holy Grail of asthma management: toward understanding how long-acting beta(2)adrenoceptor agonists enhance the clinical efficacy of inhaled corticosteroids. Medicine, British journal of pharmacology. 2008

6. Kotby MN (1986) Voice disorders: recent diagnostic advances. Egypt J Otolaryngol 3:89

7. Barnes PJ, Adcock IM (2003) How do corticosteroids work in asthma? Ann Intern Med 139(5 Pt 1):359-370

8. Natasha Mirza, Sandra Kasper Schwartz MS, Danielle Antin-Ozerkis: Laryngeal findings in users of combination corticosteroid and bronchodilator therapy. 03 January 2009.

9. Lavy JA, Wood G, Rubin JS, Harries M (2000) Dysphonia associated with inhaled steroids. J Voice 14:581-588

10. Dubus JC, Marguet C, Deschildre A, Mely L, Le Roux P, Brouard J et al (2001) Local side-effects of inhaled corticosteroids in asthmatic children: influence of drug, dose, age and device. Allergy 56:944-948

11. Almaraghy AAA, Seliem A, Khalifa RA et al (2012) The Egyptian Journal of Otolaryngology 28:270-274

12. Dogan M, Eryuksel E, Kocak I, Celikel T, Sehitoglu MA (2007) Subjective and objective evaluation of voice quality in patients with asthma. J Voice 21: 224-230

13. Hanania NA, Chapman KR, Kesten S (1995) Adverse effects of inhaled corticosteroids. Am J Med 98:196-208

14. Koike Y, Takahashi H, Calcaterra TC (1999) Acoustic measure for detecting laryngeal pathology. Acta Otolaryngol 84:105-107

15. Roland NJ, Bhalla RK, Earis J (2004) The local side effects of inhaled corticosteroids: current understanding and review of the literature. Chest 126:213-219

16. Rachelefsky G (2006) Inhaled corticosteroids and the risk of oropharyngeal adverse events: results from a meta-analysis. J Allergy Asthma Immunol 117:358
17. Saeed AM, Riad NM, Osman NM, Khattab AN, Mohammed SE (2018) Study of voice disorders in patients with bronchial asthma and chronic obstructive pulmonary disease. Egypt J Bronchol 12:20-26

\section{Publisher's Note}

Springer Nature remains neutral with regard to jurisdictional claims in published maps and institutional affiliations.

\section{Submit your manuscript to a SpringerOpen ${ }^{\circ}$ journal and benefit from:}

- Convenient online submission

- Rigorous peer review

- Open access: articles freely available online

- High visibility within the field

- Retaining the copyright to your article

Submit your next manuscript at $\boldsymbol{\nabla}$ springeropen.com 